\title{
Isolation and Characterization of Endophytic Fungi from Purslane and the Effects of Isolates on the Growth of the Host
}

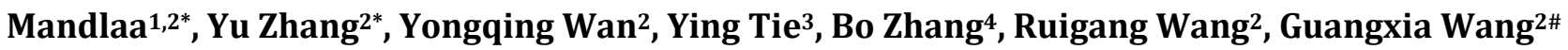 \\ ${ }^{1}$ College of Food Science and Engineering, Inner Mongolia Agricultural University, Hohhot, China \\ ${ }^{2}$ Inner Mongolia Key Laboratory of Plant Stress Physiology and Molecular Biology, Inner Mongolia Agricultural University, China \\ ${ }^{3}$ Hesheng (Inner Mongolia) Ecological Silviculture Co., Ltd., China \\ ${ }^{4}$ Research Institute of Hesheng (Inner Mongolia) Ecological Silviculture Co., Ltd., China \\ Email: "wgx200109@163.com
}

How to cite this paper: Mandlaa, Zhang, Y., Wan, Y.Q., Tie, Y., Zhang, B., Wang, R.G. and Wang, G.X. (2019) Isolation and Characterization of Endophytic Fungi from Purslane and the Effects of Isolates on the Growth of the Host. Advances in Microbiology, 9, 438-453.

https://doi.org/10.4236/aim.2019.95026

Received: April 11, 2019

Accepted: May 13, 2019

Published: May 16, 2019

Copyright $\odot 2019$ by author(s) and Scientific Research Publishing Inc. This work is licensed under the Creative Commons Attribution International License (CC BY 4.0).

http://creativecommons.org/licenses/by/4.0/

\section{(c) (i) Open Access}

\begin{abstract}
Purslane, a common weed, has been used as food or folk medicine in many countries. The growth, medicinal components and nutrient contents of the plant are closely associated with endophytes, especially endophytic fungi. In this study, the endophytic fungi associated with purslane were isolated, and the effects of the isolates on the host were investigated to lay a foundation for further research and development of purslane resources. The results showed that a total of eight endophytic fungi were isolated from purslane (collected from Hohhot, Inner Mongolia, China), and they belonged to the genera Penicillium (isolates K, N, P, $\mathrm{M}$ and I), Chaetomium (isolate J), Fusarium (isolate $\mathrm{H}$ ) and Petriella (isolate $\mathrm{O}$ ). Moreover, the growth of purslane was significantly influenced by its endophytic fungi. Isolate $\mathrm{M}$ can significantly decrease the germination rate, while $J$ can significantly increase the germination rate of purslane. In addition, $\mathrm{H}, \mathrm{J}$ and $\mathrm{M}$ can significantly increase the bud length of purslane, and the fermentation broth of $P$ has a negative influence on the bud length of purslane. $M$ and I can significantly increase the height, fresh weight and chlorophyll content of purslane due, in part, to the lower $\mathrm{pH}$ of the fermentation broth of I and $\mathrm{M}$.
\end{abstract}

\section{Keywords}

Endophytic Fungi, Purslane, Portulaca oleracea L., Growth Promotion, Germination

\section{Introduction}

Endophytes are microorganisms that reside within the tissue of living plants

${ }^{*}$ Mandlaa and Yu Zhang contributed equally to this work. 
without any symptoms [1] [2] and endophyte-free plants are currently unknown in nature [3]. It is reported that many medicinal components or the nutrient content of plants are closely associated with endophytes, especially endophytic fungi [4]. The representative example is Taxol, an anticancer drug, which is produced by Taxomyces andreanae, an endophytic fungus of Pacific yew [5]. Based on the potential for application to medicine or agriculture, studies of endophytes have received increasing attention [6] [7]. The diversity of functional metabolites produced by endophytes is reviewed by Tan [4], and more than ten different kinds of metabolites related to endophytes can be found in a variety of plants. In addition, it has been shown that endophytes have positive effects on the host [6], with the nutrients [8] [9], hormones [10] [11] and antibiotics [12] [13] provided by the endophyte being able to promote the growth of the host and protect against pathogens.

Purslane (Portulaca oleracea L.), which belongs to the Portulacaceae family [14], is a common plant throughout the world. It has been used as food and as folk medicine in many countries [15] and is also a common weed in North America [16]. It has been reported that a polysaccharide component of purslane has antitumor effects in an in vivo model [17] and that extracts of the aerial parts (dried leaves and stems) of purslane have analgesic and anti-inflammatory effects [18] [19]. Furthermore, five alkaloids have been isolated from purslane [15], which are the active ingredients of many medicinal plants.

It has been proven that functional natural products can be found in various endophytes [4] [20] [21]. However, the relationships between the medical functions and the endophytes of purslane are still unknown. Basic studies investigating the diversity of the endophytes in purslane are needed. In addition, there are few reports about the endophytes of purslane and the effects of those endophytes on the growth of the host. In our previous study, the endophytic bacteria in purslane were isolated and were found to belong to six genera: Enterobacter, Bacillus, Achromobacter, Paenibacillus, Leifsonia and Rhodanobacter [22]. Therefore, it is important to further study the endophytic fungi of purslane and improve upon the knowledge of the endophytes of purslane.

In this study, the diversity of culturable endophytic fungi of purslane and the effects of those endophytic fungi on the growth of their host are investigated. This study will provide some basic references for management of the plant and for expanding the potential use of purslane as a human or animal food, as a pharmacological agent in medicine and in the biocontrol of weeds.

\section{Materials and Methods}

\subsection{Plant Material}

Plants were obtained from 3 different locations in Hohhot of Inner Mongolia, China (41.44 N, 111.69 E): Saihan, Yuquan and Haorenger districts in July 2014. Plants were transported to the laboratory (Inner Mongolia Key Laboratory of Plant Stress Physiology and Molecular Biology, Inner Mongolia Agricultural 
University, China), where they were processed for endophyte isolation in less than $24 \mathrm{~h}$.

\subsection{Endophytic Fungus Isolation}

Surface-sterilization of the stem, root and leaf of purslane was conducted using the following procedure. First, after washing with tap water to remove any attachments, the stems, roots and leaves of purslane were surface-sterilized in an ethanol solution $(75 \%, \mathrm{v} / \mathrm{v})$ for $2 \mathrm{~min}$ and then washed 2 - 3 times with sterilized water. Second, a sodium hypochlorite solution $(2 \%, w / v)$ was applied for $1 \mathrm{~min}$ to surface-sterilize the tissue. The sodium hypochlorite residue on the tissues and leaves was removed with sterilized water. Finally, the tissues and leaves were dried on sterilized filter-paper and segmented to $0.5 \mathrm{~cm}$. The sterile water from the last wash was inoculated onto a fresh PDA plate to test the results of the surface-sterilization. After surface-sterilization, the stem and root tissues were placed onto a PDA plate. The leaves were homogenized after surface-sterilized, and the homogenate was diluted in different ratios with sterile water and spread onto a PDA plate. All PDA plates were cultured at $28^{\circ} \mathrm{C}$ in the dark.

\subsection{Endophytic Fungi Characterization}

After purification, a three-point inoculation method was used to culture the endophytes, and the colony morphology was visually observed. The hyphae of endophytes were observed under a microscope. In addition, the isolates were identified with nucleotide sequencing. The genomic DNA of the isolates was extracted using a fungal DNA extraction kit (Omega) according to the manufacturer's protocol, and polymerase chain reaction (PCR) was performed according to an established protocol [23]. The ITS region of the genomic DNA of the isolates was amplified with the primers ITS1 and ITS4 (ITS1: 5'-TCCGTAGGTGAACCTGCGG-3', ITS4: 5'-TCCTCCGCTTATTGATATGC-3'). All amplified sequences (commercial sequencing services) were aligned using BLAST in NCBI, and alignments that were more than $97 \%$ identical were selected to identify the species of the isolates. Neighbor-joining (NJ) phylogenetic trees were constructed in MEGA7 using 1000 bootstrap replicates.

\subsection{Surface-Sterilization of Seed}

To determine the optimal sterilization time, chlorine gas was used to sterilize the purslane seeds. First, purslane seeds in open centrifuge tubes were placed in a beaker. Second, chlorine gas was generated with a saturated solution of sodium hypochlorite and chlorane in a dryer, and the beaker was placed in the dryer. Finally, the chlorane was added to the beaker after two hours to produce chlorine gas. After different times of sterilization $(0,2,4,6,10,12,16,18,20$ and 24 h), 100 purslane seeds were inoculated into $1 / 2 \mathrm{MS}$ medium, and the rates of germination and survival were calculated to evaluate the effect of sterilization after $48 \mathrm{~h}$ of cultivation. The rates of germination and survival were calculated as 
follows: Germinated seeds divided by the total number of seeds and seeds forming colonies in 1/2 MS medium divided by the total number of seeds, respectively.

\subsection{Preparation of Fermentation Broth}

The isolates were inoculated into liquid PDA medium and cultured at $28^{\circ} \mathrm{C}$ and $180 \mathrm{rpm}$. After $6 \mathrm{~d}$ of cultivation, the supernatants of the isolates were obtained by centrifugation and then filtered through gauze filters (4 layers) to remove the hyphae and stored at $4^{\circ} \mathrm{C}$. The $\mathrm{pH}$ of the fermentation broth of the isolates was determined using a $\mathrm{pH}$ meter. The fermentation broth was diluted 10 -fold with sterile water to investigate the effect of fermentation broth on the seed germination rate, the bud length and the growth of purslane.

The sterilized purslane seeds were planted in sterile soil (soil:vermiculite = 1:2) with 5 seeds per pot. Then, $100 \mathrm{ml}$ of fermentation broth (diluted 10-fold with sterile water) was added to the treatment group, and $100 \mathrm{ml}$ of PDA medium (diluted 10-fold with sterile water) was added to the control group once a week. The plants were cultured under greenhouse conditions (16-hlight/8-h-dark cycle, $22^{\circ} \mathrm{C}$ and Humidity 50\%). The plant height, fresh weight and concentration of chlorophyll were determined on the 21st and 60th days. Chlorophyll determination was performed as reported by Porra et al. [24] and Wu et al. [22]

\subsection{Statistical Analysis}

Three replicates were performed for all treatments. Differences between two groups were regarded as statistically significant if $\mathrm{P}<0.05$. Microsoft Office Excel 2007 was used to analyze the data and draw the figures.

\section{Results}

\subsection{Identification of Endophytic Fungi}

After cultivation, no microbial colonies were observed on the PDA (potato dextrose agar) plates inoculated with the final rinse solution of surface-sterilization, proving that the surface-sterilization method was feasible and that the isolates were endophytic fungi of purslane. After several rounds of purification, a total of 18 isolates were obtained. Some isolates were initially considered to be the same species based on colony morphology and color by referencing the Fungal Identification Handbook [25]. Finally, eight different isolates were obtained from the samples (three from roots, two from stems and three from leaves, respectively). The results are shown in Figure 1 and Table 1.

A common method for identifying fungal species is by aligning the ITS region with known sequences in GenBank in combination with the morphological analysis. In this study, eight endophytic fungi were isolated from purslane. The results of the alignments are shown in Figure 2. When integrated with the results of morphological analysis (Table 1): $\mathrm{H}$ was identified as Fusarium oxysporum; I was identified as Penicillium ochrochloron; J was identified as Chaetomium globosum; $\mathrm{K}$ was identified as Penicillium citreonigrum; $\mathrm{M}$ was identified 


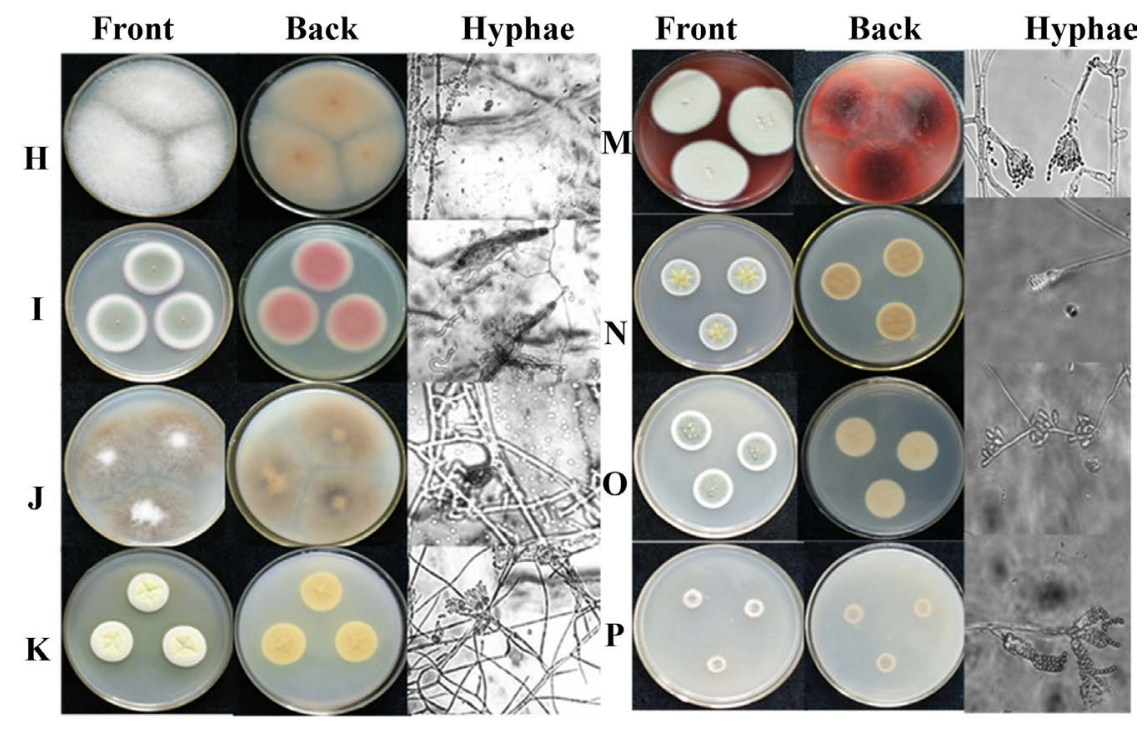

Figure 1. The colonial morphology of isolates.

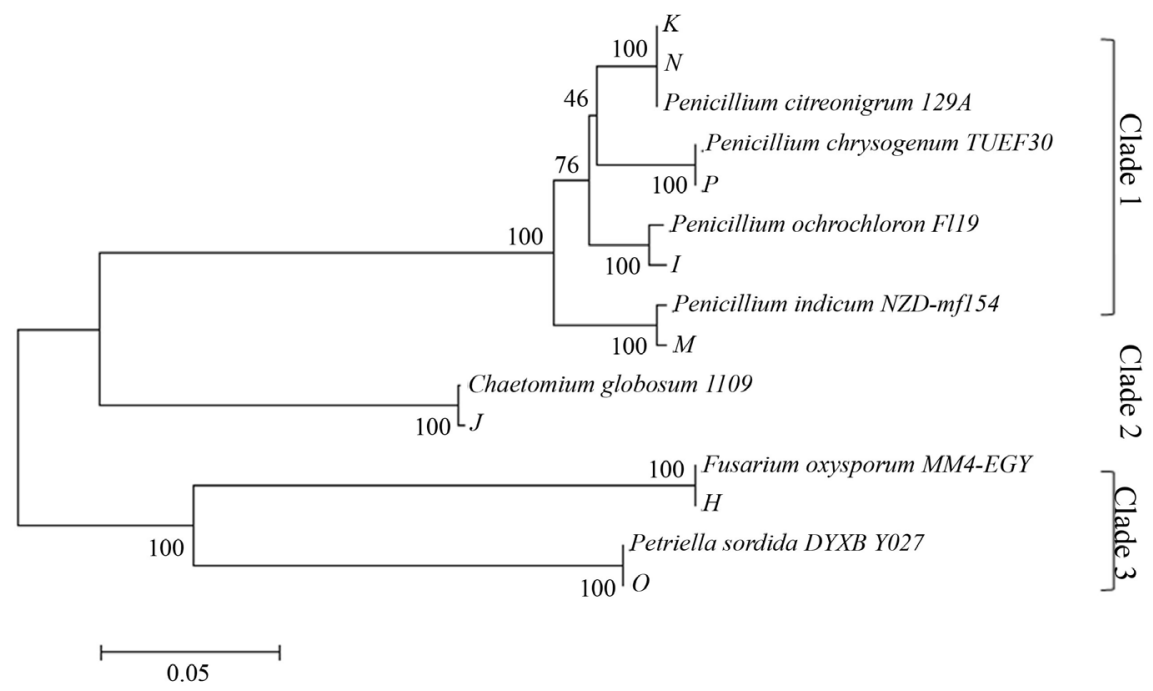

Figure 2. Phylogenetic N-J tree inferred from ITS rDNA sequences of the isolates.

Table 1. The description of colonial morphology of isolates.

\begin{tabular}{|c|c|c|c|}
\hline Position & Strain & Description of colony & Description of hyphae \\
\hline \multirow{3}{*}{ Root } & $\mathrm{H}$ & $\begin{array}{l}\text { The colony was white and structure was cotton-like. The back } \\
\text { of colony was yellow. }\end{array}$ & $\begin{array}{l}\text { The conidiophores were short } \\
\text { without branch and had two kinds of conidia. }\end{array}$ \\
\hline & J & $\begin{array}{l}\text { The colony was brown and gradually } \\
\text { generated white hyphae with irregular } \\
\text { margins. The back of colony was and brown. }\end{array}$ & $\begin{array}{l}\text { The perithecium was black and spherical. The as- } \\
\text { cus was clavate and ascospores were spin- } \\
\text { dle-shaped. }\end{array}$ \\
\hline & $\mathrm{O}$ & $\begin{array}{l}\text { The colony was dark green and the edge of colony was white } \\
\text { with regular margins. The back of colony was yellow. }\end{array}$ & $\begin{array}{l}\text { There were condias on } \\
\text { conidiophores and the conidia were oval. }\end{array}$ \\
\hline Stem & K & $\begin{array}{l}\text { The colony was white and gradually become light yellow with } \\
\text { regular margins. The back of colony was yellow. }\end{array}$ & $\begin{array}{l}\text { There are branches on the } \\
\text { conidiophores and the conidia were spherical and } \\
\text { single spore. }\end{array}$ \\
\hline
\end{tabular}




\begin{tabular}{|c|c|c|c|}
\hline & $\mathrm{N}$ & $\begin{array}{l}\text { The colony had three kinds of colors: Center was yellow, } \\
\text { middle was green and edge was white with regular margins. } \\
\text { Water drops colored light yellow could be seen on the colony. } \\
\text { The back of colony was } \\
\text { yellowish-brown. }\end{array}$ & $\begin{array}{l}\text { There are branches on the top of conidiophores } \\
\text { and the conidia were spherical and single spore. } \\
\text { Hyphae were no septum. }\end{array}$ \\
\hline \multirow{3}{*}{ leaf } & $\mathrm{M}$ & $\begin{array}{l}\text { The colony was white in initial stage and gradually become } \\
\text { gray with regular margins. The back of colony was dark red. }\end{array}$ & $\begin{array}{l}\text { The conidiophores were short with branch on the } \\
\text { top and the conidia were spherical and single } \\
\text { spore. } \\
\text { Hyphae were no septum. }\end{array}$ \\
\hline & $\mathrm{P}$ & $\begin{array}{l}\text { Compare with other isolates, the colony was small. The color } \\
\text { of colony in the center was brown and in the edge was white } \\
\text { with } \\
\text { irregular margins. The color of the back of colony was gray in } \\
\text { center and white in edge respectively. }\end{array}$ & $\begin{array}{l}\text { The conidiophores had short branches and the } \\
\text { conidia were spherical, single spore. Hyphae had } \\
\text { septum. }\end{array}$ \\
\hline & I & $\begin{array}{l}\text { The color of colony was white in initial stage and gradually } \\
\text { become dark green with } \\
\text { regular margins. The back of the colony was pink. }\end{array}$ & $\begin{array}{l}\text { The conidiophores were short without branch and } \\
\text { the conidia were spherical, single spore. }\end{array}$ \\
\hline
\end{tabular}

as Penicillium indicum; $\mathrm{N}$ was identified as Penicillium citreonigrum; $\mathrm{O}$ was identified as Petriella sordid, and $\mathrm{P}$ was identified as Penicillium chrysogenum. Furthermore, the isolates can be divided into three clades, namely: Hypocreomycetidae ( $\mathrm{H}$ and $\mathrm{O})$, Sordariomycetidae $(\mathrm{J})$ and Eurotiales (K, N, P, I and $\mathrm{M}$ ), by taxonomy.

\subsection{The Effect of the Endophytic Fungi on the Host}

The results of the sterilization of purslane seeds are shown in Figure 3. When the sterilization time was $0 \mathrm{~h}$ and $2 \mathrm{~h}$, there were still the same number microbes on the purslane seeds. Prolonging the sterilization time can significantly reduce the survival rate of microbes on the surface of purslane seeds, and the microbes present on the seeds of purslane are completely inactivated after more than $4 \mathrm{~h}$ of sterilization. However, the germination rate of purslane seeds can be reduced by the increase in sterilization times. Sterilization times of more than $12 \mathrm{~h}$ can significantly reduce the germination rates of purslane seeds. Therefore, in order to ensure the effectiveness of seed sterilization and to minimize the harm caused by the sterilization time, we selected $6 \mathrm{~h}$ as the best sterilization time for purslane seeds. In addition, seeds collected from the open field are often contaminated with fungi and bacteria, which can influence the germination rate of seeds. The sterilization time $(2-12 \mathrm{~h})$ by chlorine gas has positive effects on the germination rate of purslane seed, as shown in Figure 3. This can probably be explained by the fact that chlorine gas can inactivate microbes that are harmful to the germination of purslane seeds.

After $6 \mathrm{~h}$ of sterilization, the fermentation broth of endophytic fungi was added to the purslane seeds to investigate its effects on the germination rate and bud length of the purslane seeds. The results are shown in Figure 4. The fermentation 


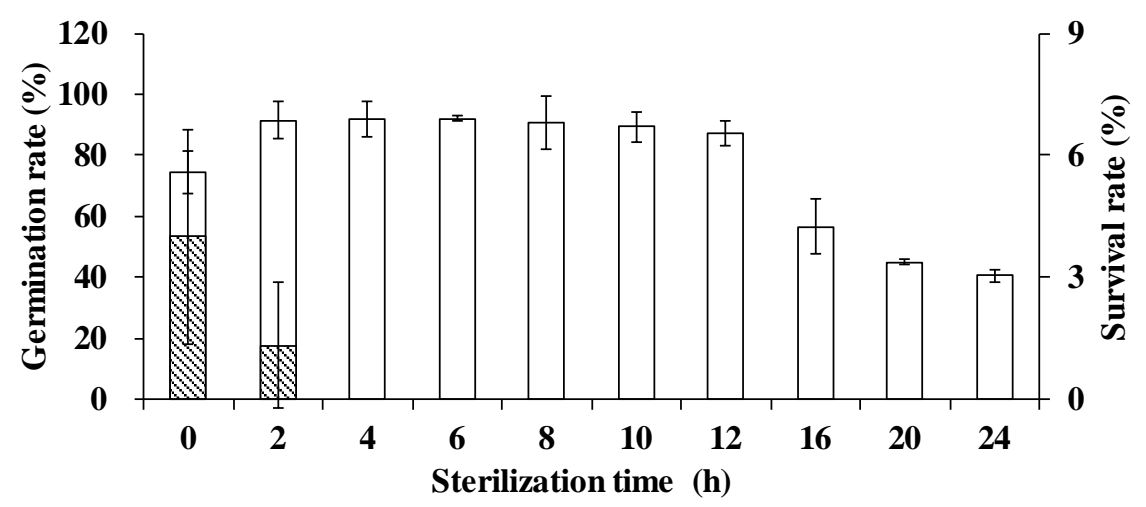

Figure 3. The effect of sterilization time on the germination rate of purslane seed and survival rate of microbial on purslane seed. The filled bar is germination rate and the open bar is survival rate of microbes on the surface of purslane seeds.

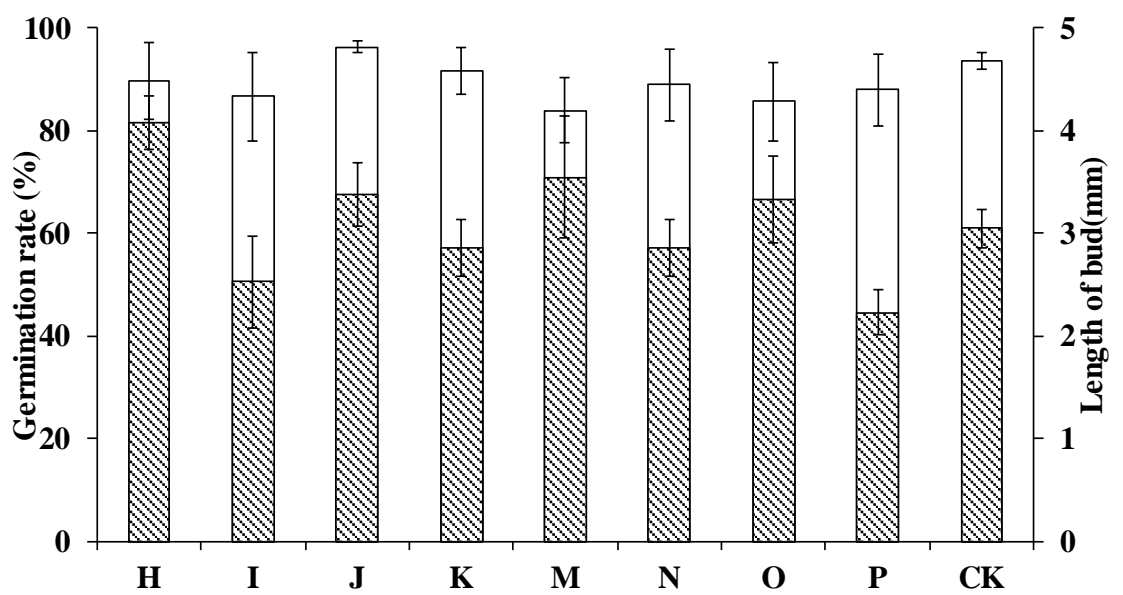

Figure 4. The effect of endophyte on the germination rate and bud length of purslane seed. The filled bar is germination rate and the open bar is length of bud.

broths of $\mathrm{J}$ and $\mathrm{M}$ significantly influenced the germination rate of purslane seeds. The germination rate was increased by $2.83 \%$ in treatment $J$ and decreased by 9.97\% in treatment $\mathrm{M}$ when compared with that of CK. The length of the bud was significantly influenced by the addition of the fermentation broths of $\mathrm{H}, \mathrm{J}, \mathrm{M}$ and $\mathrm{P}$. The addition of the fermentation broths of $\mathrm{H}, \mathrm{J}$ and $\mathrm{M}$ can significantly increase the bud length of purslane, while the fermentation broth of $\mathrm{P}$ had a negative influence on the bud length of purslane. In this study, J was identified as $F$. oxysporum and can probably produce polysaccharides to promote the growth of purslane buds, although this needs to be confirmed in future work.

The effect of endophytes on the growth of the host was investigated, and the fresh weight, height and chlorophyll content were measured at 21 and $60 \mathrm{~d}$ after the addition of the fermentation broths from the isolates. After $21 \mathrm{~d}$ of treatment, the fresh weight was increased by $47.02 \%, 72.64 \%$ and $58.04 \%$ with the addition of fermentation broths from I, M and O, respectively (Figure 5(a)). Addition of the fermentation broth of the isolates does not significantly influence the height and chlorophyll content of purslane after $21 \mathrm{~d}$ of cultivation 

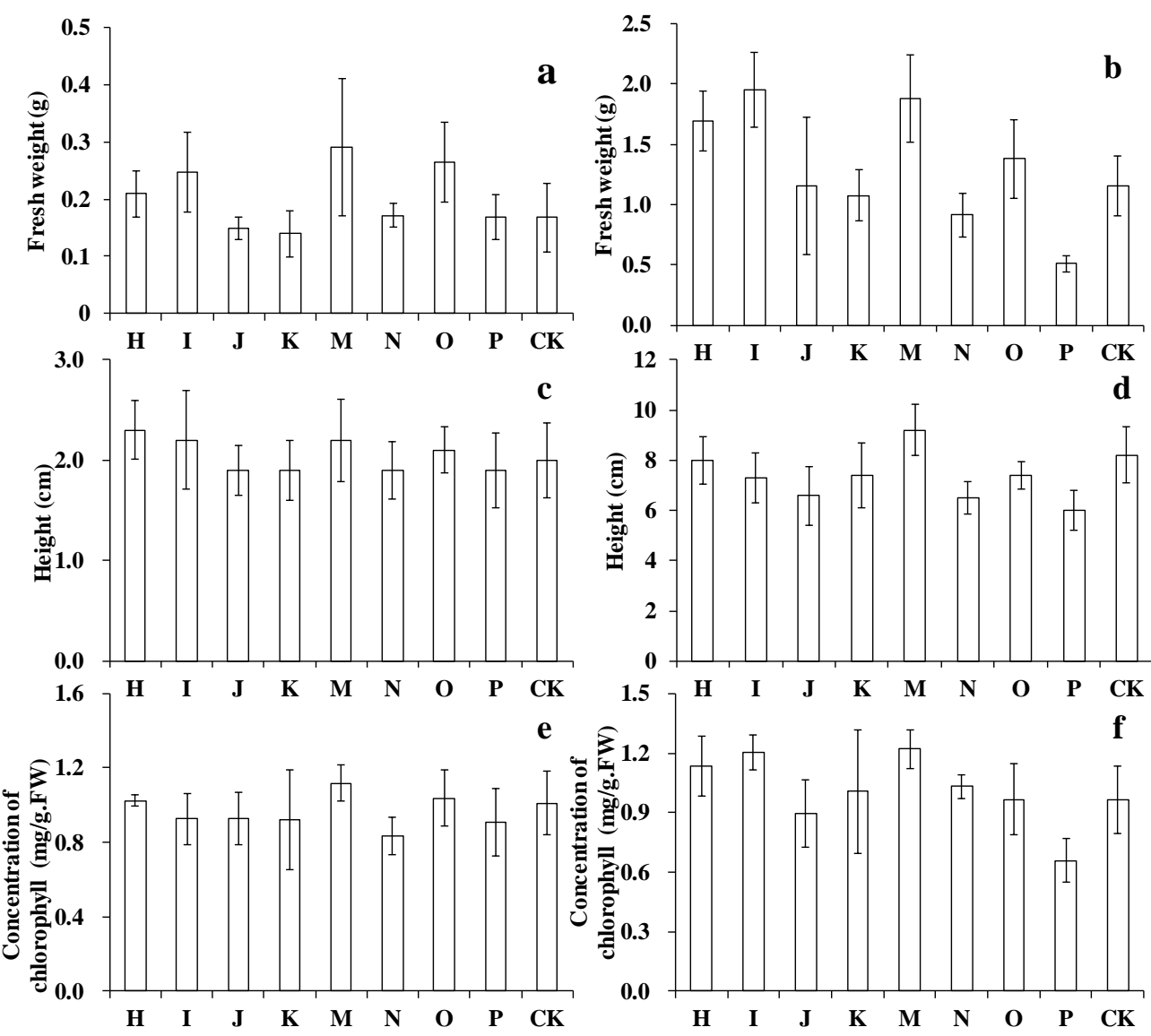

Figure 5. The effect of endophyte on the height, fresh weight and chlorophyll content of purslane.

(Figure 5(c) and Figure 5(e)). After $60 \mathrm{~d}$ of treatment with the fermentation broths of the isolates, there were significant differences in the fresh weight, height and chlorophyll content. The fermentation broths of $\mathrm{H}$, I, and $\mathrm{M}$ can significantly increase the fresh weight of purslane, while the fermentation broth of $\mathrm{P}$ can significantly inhibit the growth of purslane when compared with that of $\mathrm{CK}$. The fresh weight of purslane to which the fermentation broth of $\mathrm{P}$ decreased by $55.90 \%$ when compared with that of CK (Figure $5(\mathrm{~b})$ ).

Furthermore, the addition of the fermentation broth of $\mathrm{M}$ can significantly increase the height of purslane (by 12.19\%). However, the addition of the fermentation broths of I, J, N, O and P significantly decreased the height of purslane by $11.19 \%, 19.85 \%, 20.77 \%, 9.56 \%$ and $26.28 \%$, respectively, when compared with the height of CK (Figure 5(d)). The effects of the isolates on the appearance of purslane are shown in Figure 6. In this work, isolates $M$ and I can significantly increase the height, fresh weight and chlorophyll content of purslane, as can be observed in Figure 5, whereas M had a significant negative influence on the germination of purslane (Figure 4). To obtain further information about the mechanism of promoting growth, the $\mathrm{pH}$ of the fermentation broths of $\mathrm{M}$ and I was determined, and it was found that $\mathrm{M}$ and I can both significantly decrease the $\mathrm{pH}$ of the fermentation broth (Figure 7). 


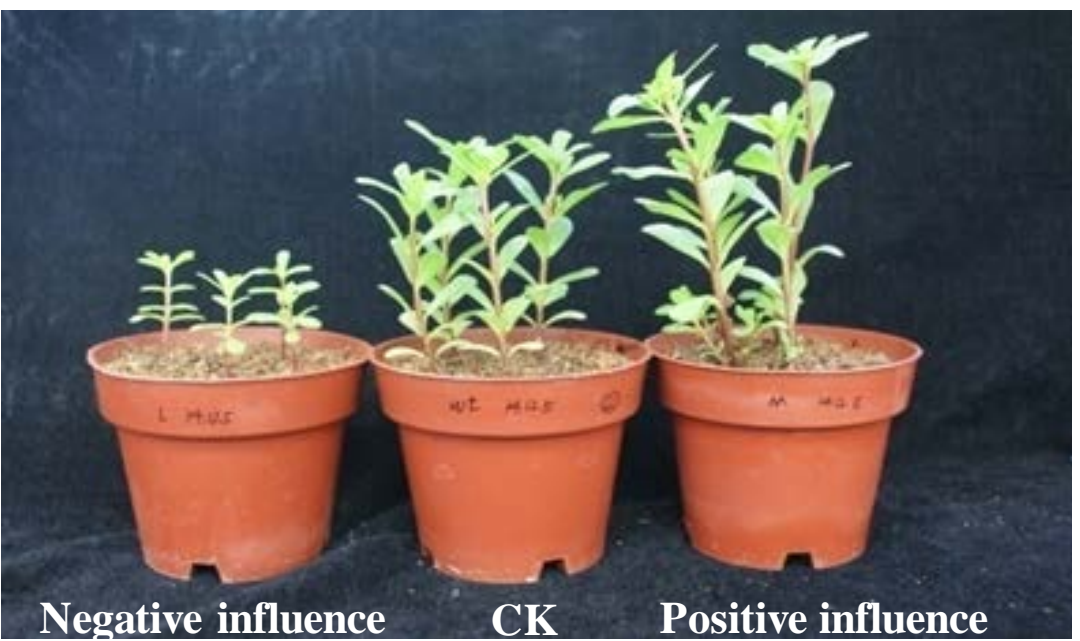

Figure 6. The effect of isolates on the appearance of purslane.

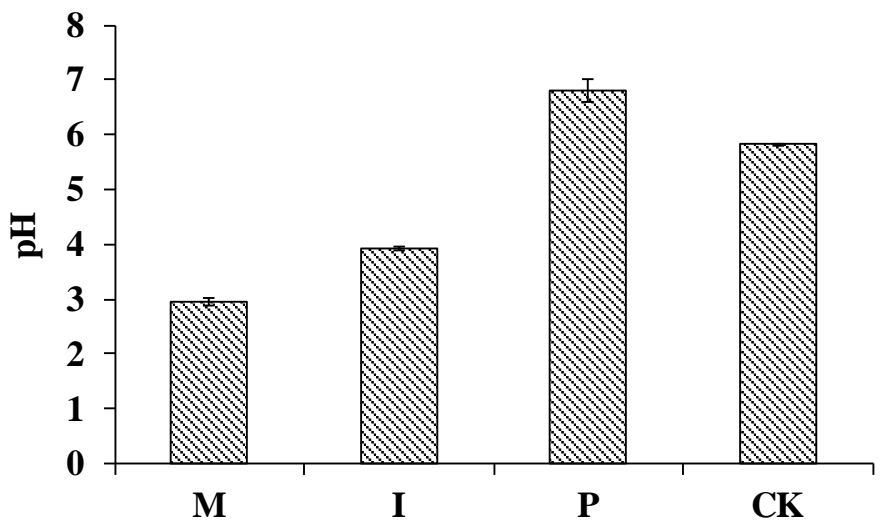

Figure 7. The effect of $\mathrm{M}$ and $\mathrm{I}$ on the $\mathrm{pH}$ of medium.

\section{Discussions}

Penicillium is a common genus of endophytic fungi found in plants, [26] and most species can inhibit the growth of other microorganisms or secrete metabolites that promote the growth of plants. Radhakrishnan and his coworker reported a strain of Penicillium sp. that was isolated from the rhizosphere soil of peanuts and can promote the growth and enhance the ability of sesame (Sesamum indicum L.) to resist salt stress by secreting various of amino acids and antagonizing pathogenic fungi [8].

In this study, four species of the Penicillium genus were isolated from purslane, and most of them were isolated from the stem and leaf. There was no $P e$ nicillium species isolated as endophytic fungi from the roots of purslane in this study. The species $P$. ochrochloron, $P$. citreonigrum and $P$. chrysogenum have been isolated as endophytic fungi in several plants and algae [27]. However, this is the first report in which $P$. indicum was isolated as an endophytic fungus. There have been few studies on $P$. indicum, especially as endophytic fungi. The first report about $P$. indicum was published in 1936, where it was isolated from sputum [28]. 
Some strains of $P$. ochrochloron were found to have inhibitory effects on the growth of gram-positive and gram-negative bacteria, as well as against fungi through the secretion of chitinase or other metabolites [29] [30]. P. chrysogenum was known as an industrial penicillin production strain [31], and it has been reported that the secondary metabolites of $P$. chrysogenum, an endophytic fungus isolated from a red alga, can inhibit the growth of the pathogen Alternaria brassicae [32]. P. chrysogenum MTCC 5108 was an endophytic fungus isolated from the mangrove plant Porteresia coarctata, and its culture medium showed significant activity against Vibrio cholera, the causative agent of cholera [33]. Some strains of $P$. citreonigrum can secrete several kinds of metabolites, which can inhibit the growth of Staphylococcus epidermidis and Candida strains [34]. In addition, some metabolites of $P$. citreonigrum can also inhibit the growth of the HepG2 cell line [35].

F. oxysporum was identified as an endophytic fungus in wild banana (Musa acuminata) roots [10] [36] and Juniperus recurva [37]. Some studies have shown that the polysaccharides produced by $F$. oxysporum can significantly promote the sprout growth of Faopyrum tataricum [38]. Strain J was identified as Chaetomium globosum in this study, and it has been reported that endophytic Chaetomium sp. isolated from wheat leaves can reduce the development of disease caused by Pyrenophora triticirepentis in wheat leaves [37]. Some species of endophytic Chaetomium sp. were confirmed to enhance the resistance to copper stress in maize seedlings [39]. The endophytic Petriella spp. isolated from Pinus roxburgii was initially identified by Altschul et al. [40] and some species of this genus can produce petriellin A, an antifungal depsipeptide [41].

The diversity of endophytes is closely related to the species of plant and their location. However, the physiological mechanisms that influence endophyte diversity are still unknown [42]. In this study, a total of 18 strains of endophytic fungi were isolated, belonging to four genera. However, seven genera of endophytic fungi (Fusarium, Penicillium, Paecilomyces, Trichoderma, Cladosporium, Lasiodiplodia and Aspergillus) were isolated from the stems of purslane grown on the shore of a reservoir containing various heavy metals [43]. Few and different endophytic fungi were isolated in this study. This was probably affected by plant species, location and selection of sterilizer and sterilization time. Some components of the same plant species from different locations or conditions are often different. This phenomenon is related to both the climate and geographical location; whether it is related to the endophytes of the plant may be a future direction for study in this area.

Seed germination is a critical life stage for plant survival and timely seedling establishment [44]. A study on Lolium perenne and Festuca arundinacea showed that endophyte-infected plants had a higher rate of germination [45]. The best conditions for the germination of common purslane were studied by Hopen [46]. However, the relationship between endophytic fungi and the germination of purslane was not examined. The fermentation broth of endophytic fungi had a significant influence on the germination of purslane, indicating that the inte- 
raction between endophytic fungi and purslane began from the germination period. It has been reported that endophytes are not a strong influence on germination and that the presence of endophytes probably changes germination through an indirect effect in L. multiflorum. However, the presence of endophytes can influence the dormancy levels of seeds [47]. Several reports have suggested that plant growth is enhanced by endophytic fungi. The mechanism includes the fact that endophytic fungi can produce a variety of beneficial metabolites for plant growth and survival, such as gibberellins, indoleacetic and amino acids [11] [23] [48]. Additionally, they can secrete some antibiotics to defend their hosts from attack by certain pathogens [30] [33] Moreover, they can enhance nutrient uptake [9] and tolerance to environmental stress [42].

Photosynthesis is the main source of energy for plants, and its efficiency is related to photosynthetic pigments such as chlorophylls and carotenoids, the influence of the addition of the fermentation broth of isolates on the chlorophyll content of purslane leaves was significantly different after $60 \mathrm{~d}$ of cultivation. The addition of the fermentation broths of I and $\mathrm{M}$ could increase the concentration of chlorophyll by $25.10 \%$ and $26.77 \%$ respectively, while the addition of the fermentation broth of P significantly decreased the chlorophyll content of purslane (Figure 5(f)). It is reported that endophytic Phomopsis liquidambari can increase the chlorophyll content in rice shoots and the amounts of glutamate, threonine and alanine in rice roots under low- $\mathrm{N}$ treatment [9]. Chlorophyll synthesis begins from glutamate in plants, and sufficient glutamate is an important condition for ensuring the synthesis of chlorophyll. Therefore, the ability of an endophyte to promote nitrogen uptake may be one of the reasons for the increase in the chlorophyll content of plants, and it suggests that $\mathrm{M}$ and I can enhance the nitrogen uptake of purslane. The reduction in chlorophyll content as a result of treatment with endophyte $\mathrm{P}$ may be related to many factors, such as nutrient uptake or the secretion of harmful substances.

The growth of purslane was dependent on an adequate amount of phosphorus in the nutrient media [45] [49]. Indicating that, phosphorus was a key nutrient for purslane. In the phosphorus cycle, microbes play a crucial role in mobilizing various forms of phosphorus, and the organic acids produced by microbes can solubilize inorganic forms of phosphorus [50]. It was reported that some species of Penicillium increased the amount of phosphorus in solution by solubilizing inorganic phosphorus [51]. In addition, some studies have shown that over $60 \%$ of purslane seeds germinated between $\mathrm{pH} 5.0$ and 10.0, while no seeds germinated at $\mathrm{pH} 4.0$ [52]. The low $\mathrm{pH}$ probably provided more soluble phosphorus for the purslane seedlings, but it affected the germination of the purslane seeds.

\section{Conclusion}

In this study a total of eight species of endophytic fungi were isolated from purslane ( $\mathrm{H}$ was identified as $F$. oxysporum; I was identified as $P$. ochrochloron; J was identified as $C$. globosum; $\mathrm{K}$ was identified as $P$. citreonigrum; $\mathrm{M}$ was iden- 
tified as $P$. indicum; $\mathrm{N}$ was identified as $P$. citreonigrum; $\mathrm{O}$ was identified as $P$. sordida, and $\mathrm{P}$ was identified as $P$. chrysogenum) and were identified using morphological and molecular biological techniques. The effects of the isolates on the growth of the host plant were investigated, and it was determined that isolate $M$ can significantly decrease the germination rate, while J can significantly increase the germination rate. In addition, $\mathrm{H}, \mathrm{J}$ and $\mathrm{M}$ can significantly increase the bud length of purslane, while the fermentation broth of $\mathrm{P}$ had a negative influence on the bud length. However, M and I can significantly increase the height, fresh weight and chlorophyll content of purslane. The ability of M and I to decrease the $\mathrm{pH}$ probably was the main reason for their ability to promote growth.

\section{Funding}

Research on Vegetation Rehabilitation Technology of Gully Slope in Alpine, Arid and Semiarid Areas of North China (2017), Major Project of Huhhot Science and Technology Program, Caragana genetic modification new germplasm creation and its application in ecological restoration (KCBJ2018012), Inner Mongolia Autonomous Region Science and Technology Innovation Guidance Project and Eco-technology Integration and Industrialization Demonstration of Northern Sand Control Belt (Inner Mongolia), The Science and Technology Project of Inner Mongolia Autonomous Region.

\section{Conflicts of Interest}

The authors declare no conflicts of interest regarding the publication of this paper.

\section{References}

[1] Porras-Alfaro, A. and Bayman, P. (2011) Hidden Fungi, Emergent Properties: Endophytes and Microbiomes. Annual Review of Phytopathology, 49, 291-315. https://doi.org/10.1146/annurev-phyto-080508-081831

[2] Wilson, D. (1995) Endophyte: The Evolution of a Term, and Clarification of Its Use and Definition. Oikos, 73, 274-276. https://doi.org/10.2307/3545919

[3] Partidamartínez, L.P. and Heil, M. (2011) The Microbe-Free Plant: Fact or Artifact? Frontiers in Plant Science, 2, 100. https://doi.org/10.3389/fpls.2011.00100

[4] Tan, R.X. and Zou, W.X. (2001) Endophytes: A Rich Source of Functional Metabolites. Natural Product Reports, 18, 448-459. https://doi.org/10.1039/b1009180

[5] Stierle, A., Strobel, G. and Stierle, D. (1993) Taxol and Taxane Production by Taxomyces andreanae, an Endophytic Fungus of Pacific Yew. Science, 260, 214-216. https://doi.org/10.1126/science.8097061

[6] Schulz, B., Boyle, C., Draeger, S., et al. (2002) Endophytic Fungi: A Source of Novel Biologically Active Secondary Metabolites. Mycological Research, 106, 996-1004. https://doi.org/10.1126/science.8097061

[7] Waller, F., Achatz, B., Baltruschat, H., et al. (2005) The Endophytic Fungus Piriformospora indica Reprograms Barley to Salt-Stress Tolerance, Disease Resistance, and Higher Yield. Proceedings of the National Academy of Sciences of the United 
States of America, 102, 13386-13391. https://doi.org/10.1073/pnas.0504423102

[8] Radhakrishnan, R., Kang, S.M., Baek, I.Y., et al. (2014) Characterization of Plant Growth-Promoting Traits of Penicillium Species against the Effects of High Soil Salinity and Root Disease. Journal of Plant Interactions, 9, 754-762. https://doi.org/10.1080/17429145.2014.930524

[9] Yang, B., Wang, X.M., Ma, H.Y., et al. (2014) Effects of the Fungal Endophyte Phomopsis Liquidambari, on Nitrogen Uptake and Metabolism in Rice. Plant Growth Regulation, 73, 165-179. https://doi.org/10.1007/s10725-013-9878-4

[10] Athman, S.Y., Dubois, T., Coyne, D., et al. (2006) Effect of Endophytic Fusarium oxysporum on Host Preference of Radopholus similis to Tissue Culture Banana Plants. Journal of Nematology, 38, 455-460.

[11] Waqas, M., Khan, A.L., Kamran, M., et al. (2012) Endophytic Fungi Produce Gibberellins and Indoleacetic Acid and Promotes Host-Plant Growth during Stress. Molecules, 17, 10754-10773. https://doi.org/10.3390/molecules170910754

[12] Kharwar, R.N., Verma, V.C., Kumar, A., et al. (2009) Javanicin, an Antibacterial Naphthaquinone from an Endophytic Fungus of Neem, Chloridium sp. Current Microbiology, 58, 233-238. https://doi.org/10.1007/s00284-008-9313-7

[13] Zhang, C.L., Zheng, B.Q., Lao, J.P., et al. (2008) Clavatol and Patulin Formation as the Antagonistic Principle of Aspergillus clavatonanicus, an Endophytic Fungus of Taxus mairei. Applied Microbiology and Biotechnology, 78, 833-840. https://doi.org/10.1007/s00253-008-1371-Z

[14] İsmail, O., Figen, A.K. and Pişkin, S. (2015) Effects of Open-Air Sun Drying and Pre-Treatment on Drying Characteristics of Purslane (Portulaca oleracea L.). Heat and Mass Transfer, 51, 807-813. https://doi.org/10.1007/s00231-014-1452-8

[15] Xiang, L., Xing, D., Wang, W., et al. (2005) Alkaloids from Portulaca oleracea L. Phytochem, 66, 2595-2601. https://doi.org/10.1016/j.phytochem.2005.08.011

[16] Proctor, C.A. (2013) Biology and Control of Common Purslane (Portulaca oleracea L.). University of Nebraska-Lincoln, Lincoln.

[17] Shen, H., Tang, G., Zeng, G., et al. (2013) Purification and Characterization of an Antitumor Polysaccharide from Portulaca oleracea L. Carbohydrate Polymers, 93, 395-400. https://doi.org/10.1016/j.carbpol.2012.11.107

[18] Chan, K., Islam, M.W., Kamil, M., et al. (2000) The Analgesic and Anti-Inflammatory Effects of Portulaca oleracea L. subsp. Sativa (Haw.) Celak. Journal of Ethnopharmacology, 73, 445-451. https://doi.org/10.1016/S0378-8741(00)00318-4

[19] Meng, Y., Ying, Z., Xiang, Z., et al. (2016) The Anti-Inflammation and Pharmacokinetics of a Novel Alkaloid from Portulaca oleracea L. Journal of Pharmacy and Pharmacology, 68, 397-405. https://doi.org/10.1111/jphp.12526

[20] Taechowisan, T., Lu, C., Shen, Y. and Lumyong, S. (2007) Antitumor Activity of 4-Arylcoumarins from Endophytic Streptomyces aureofaciens CMUAc130. Journal of Cancer Research and Clinical Oncology, 3, 86-91. https://doi.org/10.4103/0973-1482.34685

[21] Weber, D., Sterner, O., Anke, T., et al. (2004) Phomol, a New Antiinflammatory, Metabolite from an Endophyte of the Medicinal Plant Erythrina cristagalli. Cheminform, 57, 559-563. https://doi.org/10.7164/antibiotics.57.559

[22] Wu, Y., Shang, S.H., Yang, Q., et al. (2014) Isolation and Identification of Endophytic Bacteria from Purslane. Journal of Shanxi Agricultural University, 34, 117-120. (In Chinese) 
[23] Radhakrishnan, R., Shim, K.B., Lee, B.W., et al. (2013) IAA Producing Penicillium sp. NICS01 Triggers Plant Growth and Suppresses Fusarium sp.-Induced Oxidative Stress Insesame (Sesamum indicum L.). Journal of Microbiology and Biotechnology, 23, 856-863. https://doi.org/10.4014/jmb.1209.09045

[24] Porra, R.J., Thompson, W.A. and Kriedemann, P.E. (1989) Determination of Accurate Extinction Coefficients and Simultaneous Equations for Assaying Chlorophylls $\mathrm{a}$ and $\mathrm{b}$ Extracted with Four Different Solvents: Verification of the Concentration of Chlorophyll Standards by Atomic Absorption Spectroscopy. Biochimica et Biophysica Acta, 975, 384-394. https://doi.org/10.1016/S0005-2728(89)80347-0

[25] Wei, J.C. (1979) Handbook of Fungal Identification. Shanghai Science and Technology Press, Shanghai.

[26] Zhao, L., Xu, Y., Lai, X.H., et al. (2015) Screening and Characterization of Endophytic Bacillus and Paenibacillus Strains from Medicinal Plant Lonicera japonica for Use as Potential Plant Growth Promoters. Brazilian Journal of Microbiology, 46, 977-989. https://doi.org/10.1590/S1517-838246420140024

[27] Hamayun, M., Khan, S.A., Iqbal, I., et al. (2010) Isolation of a Gibberellin-Producing Fungus (Penicillium sp. MH7) and Growth Promotion of Crown Daisy (Chrysanthemum coronarium). Journal of Microbiology and Biotechnology, 20, 202-207. https://doi.org/10.4014/jmb.0905.05040

[28] Sandhu, D.K.S. and Hu, R.S.A. (1963) New Species of Penicillium Isolated from Sputum. Canadian Journal of Botany, 41, 1273-1274. https://doi.org/10.1139/b63-105

[29] Patil, N.S., Waghmare, S.R. and Jadhav, J.P. (2013) Purification and Characterization of an Extracellular Antifungal Chitinase from Penicillium ochrochloron MTCC 517 and Its Application in Protoplast Formation. Process Biochemistry, 48, 176-183. https://doi.org/10.1016/j.procbio.2012.11.017

[30] Rančić, A., Soković, M., Karioti, A., et al. (2006) Isolation and Structural Elucidation of Two Secondary Metabolites from the Filamentous Fungus Penicillium ochrochloron with Antimicrobial Activity. Environmental Toxicology and Pharmacology, 22, 80-84. https://doi.org/10.1016/j.etap.2005.12.003

[31] Van den Berg, M.A., Albang, R., Albermann, K., et al. (2008) Genome Sequencing and Analysis of the Filamentous Fungus Penicillium chrysogenum. Nature Biotechnology, 26, 1161-1168. https://doi.org/10.1038/nbt.1498

[32] Gao, S.S., Li, X.M., Du, F.Y., et al. (2011) Secondary Metabolites from a Marine-Derived Endophytic Fungus Penicillium chrysogenum QEN-24S. Marine Drugs, 9, 59-70. https://doi.org/10.3390/md9010059

[33] Devi, P., Rodrigues, C., Naik, C.G., et al. (2012) Isolation and Characterization of Antibacterial Compound from a Mangrove-Endophytic Fungus, Penicillium chrysogenum MTCC 5108. Indian Journal of Microbiology, 52, 617-623. https://doi.org/10.1007/s12088-012-0277-8

[34] Wang, X., Sena Filho, J.G., Hoover, A.R., et al. (2010) Chemical Epigenetics Alters the Secondary Metabolite Composition of Guttate Excreted by an Atlantic-Forest-Soil-Derived Penicillium citreonigrum. Journal of Natural Products, 73, 942-948. https://doi.org/10.1021/np100142h

[35] Yuan, W.H., Wei, Z.W., Dai, P., et al. (2014) Halogenated Metabolites Isolated from Penicillium citreonigrum. Chemistry and Biodiversity, 11, 1078-1087. https://doi.org/10.1002/cbdv.201300349

[36] Zakaria, L. (2011) Endophytic Fusarium spp. from Wild Banana (Musa acuminata) Roots. African Journal of Microbiology Research, 5, 3600-3602. 
https://doi.org/10.5897/AJMR11.298

[37] Kour, A., Shawl, A.S., Rehman, S., et al. (2008) Isolation and Identification of an Endophytic Strain of Fusarium oxysporum Producing Podophyllotoxin from Juniperus recurva. World Journal of Microbiology and Biotechnology, 24, 1115-1121. https://doi.org/10.1007/s11274-007-9582-5

[38] Zhao, J., Zhong, L., Zou, L., et al. (2014) Efficient Promotion of the Sprout Growth and Rutin Production of Tartary Buckwheat by Associated Fungal Endophytes. $\mathrm{Ce}$ real Research Communications, 42, 401-412. https://doi.org/10.1556/CRC.2013.0068

[39] Abou Alhamed, M.F. and Shebany, Y.M. (2012) Endophytic Chaetomium globosum Enhances Maize Seedling Copper Stress Tolerance. Plant Biology, 14, 859-863. https://doi.org/10.1111/j.1438-8677.2012.00608.x

[40] Altschul, S.F., Madden, T.L., Schaffer, A.A., et al. (1997) Gapped BLAST and PSI-BLAST: A New Generation of Protein Database Search Programs. Nucleic Acids Research, 25, 3389-3402. https://doi.org/10.1093/nar/25.17.3389

[41] Lee, K.K., Gloer, J.B., Scott, J.A., et al. (1995) Petriellin A: A Novel Antifungal Depsipeptide from the Coprophilous Fungus Petriella Sordid. The Journal of Organic Chemistry, 60, 5384-5385. https://doi.org/10.1021/jo00122a010

[42] Sanchez-Azofeifa, A., Oki, Y., Wilson, F.G., et al. (2012) Relationships between Endophyte Diversity and Leaf Optical Properties. Trees, 26, 291-299. https://doi.org/10.1007/s00468-011-0591-5

[43] Deng, Z., Zhang, R., Shi, Y., et al. (2014) Characterization of $\mathrm{Cd}^{-}, \mathrm{Pb}^{-}, \mathrm{Zn}^{-}$Resistant Endophytic Lasiodiplodia sp. MXSF31 from Metal Accumulating Portulaca oleracea and Its Potential in Promoting the Growth of Rape in Metal-Contaminated Soils. Environmental Science and Pollution Research, 21, 2346-2357. https://doi.org/10.1007/s11356-013-2163-2

[44] Hubbard, M., Germida, J.J. and Vujanovic, V. (2012) Fungal Endophytes Enhance Wheat Heat and Drought Tolerance in Terms of Grain Yield and Second-Generation Seed Viability. Journal of Applied Microbiology, 90, 137-149. https://doi.org/10.1139/b11-091

[45] Clay, K. (1987) Effects of Fungal Endophytes on the Seed and Seedling Biology of Lolium perenne and Festuca arundinacea. Oecologia, 73, 358-362. https://doi.org/10.1007/BF00385251

[46] Hopen, H.J. (1972) Growth of Common Purslane as Influencing Control and Importance as a Weed. Weed Science, 20, 20-23.

[47] Gundel, P.E., Maseda, P.H., Ghersa, C.M., et al. (2010) Effects of the Neotyphodium Endophyte Fungus on Dormancy and Germination Rate of Lolium multiflorum Seeds. Austral Ecology, 31, 767-775. https://doi.org/10.1111/j.1442-9993.2006.01638.x

[48] Yeon-Sik, C., In-Jung, L., Jong-Myeong, K., et al. (2008) Plant Growth Promotion and Penicillium citrinum. BMC Microbiology, 8, 589-591.

[49] Santos, B.M., Dusky, J.A., Stall, W.M., et al. (2004) Phosphorus Absorption in Lettuce, Smooth Pigweed (Amaranthus hybridus), and Common Purslane (Portulaca oleracea) Mixtures. Weed Science, 52, 389-394. https://doi.org/10.1614/WS-03-053R

[50] Kaur, C., Selvakumar, G. and Ganeshamurthy, A.N. (2016) Organic Acids in the Rhizosphere: Their Role in Phosphate Dissolution. In: Singh, D.P., Singh, H.B. and Prabha, R., Eds., Microbial Inoculants in Sustainable Agricultural Productivity, 2th 
Edition, Springer, Berlin, 165-177. https://doi.org/10.1007/978-81-322-2644-4 11

[51] Wakelin, S.A., Gupta, V.V., Harvey, P.R., et al. (2007) The Effect of Penicillium fungi on Plant Growth and Phosphorus Mobilization in Neutral to Alkaline Soils from Southern Australia. Canadian Journal of Microbiology, 53, 106.

https://doi.org/10.1139/w06-109

[52] Yang, C., Feng, L. and Yue, M. (2009) Studies on the Characteristics of Seed Germination of a Vicious Weed Species, Common Purslane. Plant Protection, 1, 62-56. (In Chinese) 